\title{
Effect of protective agents on the viability of Lactococcus lactis subjected to freeze-thawing and freeze-drying
}

\author{
Diana Berner and Helmut Viernstein \\ Department of Pharmaceutical Technology and Biopharmaceutics, University of Vienna, \\ Althanstrasse 14, A-1090 Vienna, Austria
}

\begin{abstract}
The effect of different protectants and the impact of the initial cell density on the viability of Lactococcus lactis Sr. 3.54 subjected to freeze-thawing and freezedrying was studied. Several additives were tested as protective agents against freezing and drying injuries. Maximum viability of the cells after freeze-thawing was obtained with sucrose and skim milk mixtures as protective agents (78\% viability). Freeze-drying with protectants based on skim milk or MRS-broth were most effective (survival levels $>60 \%$ ). The effect of the initial cell load on the final recovery was dependent on the protectant. Every sample showed an increase in viability when a high initial cell concentration $\left(10^{10} \mathrm{cfu} \mathrm{ml}^{-1}\right)$ was used. The blank showed a 1500 fold increase, skim milk/sucrose based lyophilisates an 1,7 fold increase in viability when the initial cell load was changed from $10^{09}$ to $10^{10} \mathrm{cfu} \mathrm{ml}^{-1}$. The use of $10^{10} \mathrm{cfu} \mathrm{ml} \mathrm{m}^{-1}$ as initial cell concentration and sucrose/skim milk as protectant yielded a lyophilisate with $71 \%$ viability. Results suggest the possibility of producing freeze dried powders of Lactococcus lactis with high viability for the food industry.
\end{abstract}

\section{Keywords}

Lactococcus lactis, freeze-drying, freeze-thawing, lactic acid bacteria, initial cell concentration 


\section{Introduction}

Adequate shelf life, high cell viability and activity are the requirements for bacterial formulations. Lactic acid bacteria and other biological materials used as starter cultures in the dairy industry or as silage preservants are often preserved by freezing and/or freezedrying resulting in products with excellent long-term stability in most cases [1]. Lyophilisation/freeze-drying is defined as a stabilizing process in which the substances are first frozen followed by a sublimation (primary drying) and desorption (secondary drying) step in order to reduce the water content to levels that will no longer support biological growth or chemical reactions [2, 3]. Dried cultures are favoured over frozen cultures because of lower transport and storage costs.

However, freeze-drying has some undesirable side effects, such as denaturation of sensitive proteins leading to decreased viability or activity. Freeze-drying subjects bacteria to two different kinds of stress. First to freezing, whereby only the free accessable water is displaced, and subsequently to drying, where even nonfreezeable water can be removed. The mechanism of protection is different for both situations $[4,5]$.

To protect bacteria from these negative effects, protective agents are commonly added prior to freezing or freeze-drying $[6,7,8,9,10,11,12,13,14,15,16,17]$. However, the protection afforded by a given additive depends on the species of microorganism.

The combined damage caused by freeze-drying can be attributed to two primary causes: changes in the physical state of the membrane lipids and protein damage or protein denaturation $[6,11]$. As water is removed from the biomembrane, the headgroups of the lipids are brought closer together and this results in increased van der Waals interaction between the acyl chains. This forces the biomembrane into the gel phase at room temperature. When rehydrated the membrane undergoes a phase transition and as a result it can become leaky. It has been suggested that sugars depress the phase transition in dry phospholipids by forming hydrogen bounds with the polar headgroups. This is known as the water replacement hypothesis. The ability of different protectants to shelter proteins from denaturation could also be due to the ability of forming hydrogen bonds with the protein when water is removed. Also, the changes in solution properties during freezing and thawing, such as the change in $\mathrm{pH}$ value at the eutectic point, can cause harm. The major damages resulting from freezing are fusion and thermotropic phase transitions of the cell membranes. Cryoprotectants can prevent this via the increase 
in the charge density around the headgroups of the biolayer and therefore inhibiting fusion by electrostatic repulsion, or they can limit fusion by steric hinderance. Beside the used protective agents the initial cell load, the rehydration media [18], as well as the growing conditions [19] influence the resulting viability after freeze-drying. Another important parameter affecting the stability of the product is the value of the water activity ( $a_{w}$-value). This value depends on the protectant as well as on the parameters of the drying process (e.g. time) and can be adjusted to a certain degree after freeze-drying. By definition the $a_{w}-$ value is the partial pressure of water in the product divided by that of pure water. At high $a_{w}$-values, the dry cell can be destroyed because solutes can diffuse in water and therefore damage the cell by an osmotic effect [20]. The aim of this study was to investigate the effect of different cryo-and lyoprotective agents on Lactococcus lactis Sr. 3.54, a strain used in ensiling and in the dairy industry, and to study the influence of the initial cell concentration on the viability of this special strain. As the potency of different protectants depends on the bacterial strain, there could be variations in results to other strains. This study is assessing potential protectants using only one strain of Lactococcus lactis.

\section{Experimental}

\section{Microorganism}

Lactococcus lactis Sr. 3.54 was obtained from Medipharm AB, Sweden.

\section{Sample preparation}

The organisms were grown in MRS-broth (Merck) at $30^{\circ} \mathrm{C}$ under anaerobic conditions to stationary phase $(24 \mathrm{~h})$; aliquots of $1 \mathrm{ml}$ were distributed in sterile vials, centrifuged at $16264 \mathrm{~g}$ for 4 minutes and washed once with physiological $\mathrm{NaCl}$ $(0,9 \%)$ solution. The pellets were resuspended in $1 \mathrm{ml}$ of protectant solution and immediately frozen at $-80^{\circ} \mathrm{C}$. Under these conditions the cell number in $1 \mathrm{ml}$ of protectant solution averaged $10^{10} \mathrm{cfu} \mathrm{ml}^{-1}$. To adjust the cell number to approximately $10^{9} \mathrm{cfu} \mathrm{ml}^{-1}, 10 \mathrm{ml}$ of the bacterial suspension were diluted with $0,9 \%$ 
$\mathrm{NaCl}$ prior to distribution in sterile vials. The samples were freeze-dried for $24 \mathrm{~h}$ in a freeze-dryer model $\mathrm{CHRIST}^{\odot} \mathrm{BETA} 1-8 \mathrm{~K}$ at a pressure of $0,1 \mathrm{~Pa}$.

\section{Suspending media}

The following compounds were tested for their protective ability:

Inorganic compounds: distilled water, physiological sodium chloride (sodium chloride extra pure, Merck, Darmstadt, D) solution, D-sorbitol (min. 98\% Sigma Aldrich, Deisenhofen, D), di-sodium hydrogen phosphate dodecahydrate (cryst. Extra pure, Merck, Darmstadt, D)

Sugars: D-(-)-fructose (min. 99\%, Sigma-Aldrich, Deisenhofen, D), D-(+)-glucosemonohydrate (for microbiology, Merck, Darmstadt, D), sucrose (min. 99\%, for molecular biology Sigma-Aldrich, Deisenhofen, D ), D-(-)-sorbitol (min. 98\%, SigmaAldrich, Deisenhofen, D), D-(-)-mannitol (for foodstuff, Merck, Darmstadt, D), lactose monohydrate (Ph. Eur., Kwizda, Vienna, A), D-(+)-maltose monohydrate (HPLC grade, Fluka, Buchs, $\mathrm{CH}$ ), maltodextrin.

Polymers: Polyvinylpyrrolidone K25 (Fluka, Buchs, CH), Dextran 4 Mr 4000-6000 (pure, Serva Feinbiochemica, Heidelberg, USA), Dextran T 70 (Pharmaceutica LKB), polyethylene glycol 400 (Hestag, Vienna, A), Tween ${ }^{\odot} 80$ (for syntheses, Merck, Darmstadt, D)

Complex media: skim milk (skim milk powder for microbiology, Merck, Darmstadt, D), MRS-broth (Merck, Darmstadt, D) and different mixtures with skim milk and MRS broth.

If not other indicated all solutions were $10 \%(\mathrm{w} / \mathrm{w})$ in distilled water unless indicated otherwise. All solutions were sterilised at $121^{\circ} \mathrm{C}$ for 15 minutes. Mixtures of skim milk in MRS broth were first sterilised and then combined. The polymer solutions were filtered sterile. All solutions with MRS broth were sterilised at $118^{\circ} \mathrm{C}$ for 15 minutes. 


\section{Rehydration and determination of the colony forming units (cfu)}

All samples were stored at $-80^{\circ} \mathrm{C}$ for a 7 days prior to freeze drying or thawing. After freeze-drying the samples were brought to their original volume with sterile physiological $\mathrm{NaCl}$ solution, incubated for 20 minutes at $30^{\circ} \mathrm{C}$. A sample was decimally diluted in physiological $\mathrm{NaCl}$ and subsequently planted onto MRS-agar. The plates were incubated anaerobically at $30^{\circ} \mathrm{C}$ for $48 \mathrm{~h}$. Then the colony forming units were counted. The survival rate was calculated as follows: viability [\%] $=$ (cfu after freeze drying)/(cfu before freeze drying)* 100 .

To estimate the protection provided for freeze-thawing, samples were thawed at $4^{\circ} \mathrm{C}$ overnight. Prior to counting, the samples were brought to room temperature. Each presented value is the mean of 5 different experiments. The estimated error was less than half an order of magnitude.

\section{Determination of the water activity ( $a_{w}$-value)}

The $a_{w}$-value was measured with a measuring unit AWX 3000/AWX 3001 (ebro electronic $\mathrm{GmbH}$, Ingolstadt, D). Directly after freeze-drying the samples were put into the measurement chamber for 90 minutes at $25^{\circ} \mathrm{C}$.

\section{Results and Discussion}

\section{Results}

\section{Viability after freeze-thawing}

As a general rule, substances that showed good lyoprotection also showed good cryoprotection. However high viability after freeze-thawing is no guarantee of high viability after lyophilisation. $10 \%$ skim milk/mannitol as protectant yielded $70 \%$ viability after freeze-thawing, but only $10 \%$ viability after lyophilisation. Using $5 \%$ mannitol in MRS-broth gave $68 \%$ viability after freeze-thawing and $62 \%$ viability after lyophilisation. As expected lyophilisates obtained with skim milk and MRSbroth based protective agents yielded the best results. The addition of physiological 
$\mathrm{NaCl}$ solution, PVP K25, and maltodextrin prior to lyophilisation resulted in a decrease in the viability even in regard to the blank.

\section{Viability after freeze-drying}

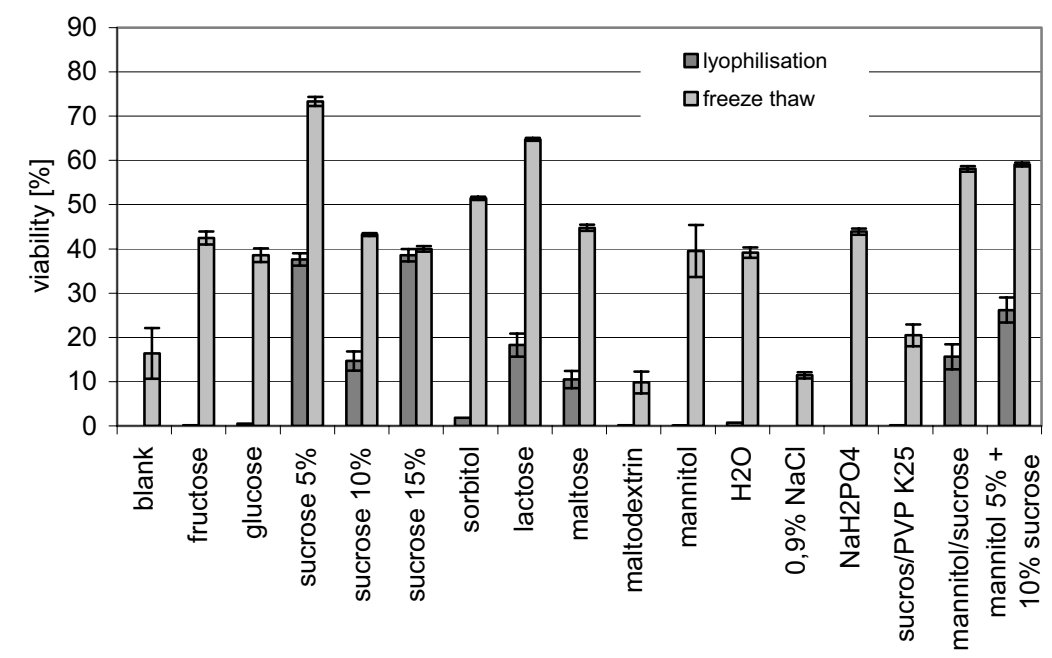

protectant

Fig. 1. Effect of different cryo- and lyoprotectants on the viability after freezethawing and freeze-drying: sugars and simple inorganic compounds. If not other indicated $10 \%(\mathrm{w} / \mathrm{w})$ solutions were used. The error bars show the standard deviation.

Preliminary tests showed that some of the polymers, although giving excellent protection to freeze-thawing (PEG 400 about 95\% viability) yielded no protection to freeze-drying. Tween ${ }^{\odot} 80$ solutions provided good cryoprotection but after lyophilisation yielded a gel-like residue which was no longer water soluble. Therefore the viability could be not estimated. Not only the viability but also the physical structure of the lyophilisate is important. On the one hand, all skim milk lyophilisates provided a freeze dried material with a light and porous structure that 
facilitaded rehydration. Mannitol and PVP K25, Dextran 4 as well as $\mathrm{NaCl}$ also yielded well-restorable products. On the other hand, sugars yielded glasslike, highly hydroscopic masses. The hydroscopicity of sugars is also important with respect to the water activity value which greatly influences the shelf life of microbial products. To improve not only the viability but also the physical structure, mixtures of good bulking agents (e.g. skim milk, mannitol) and good lyoprotectants (sugars) were used.

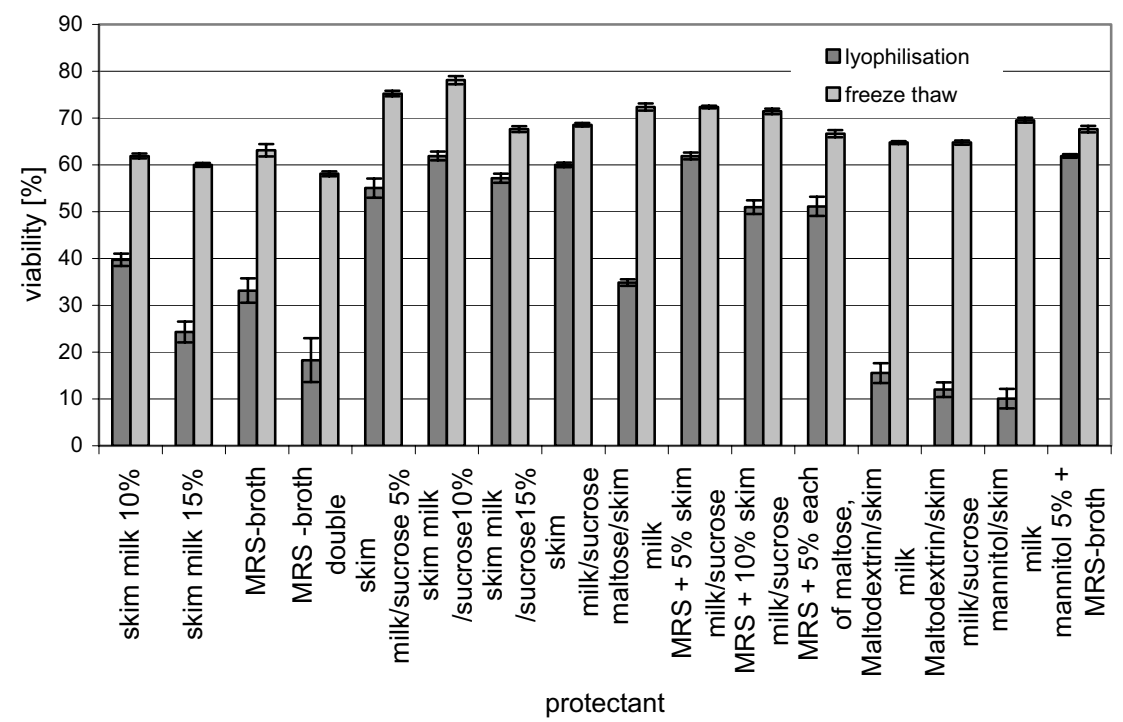

Fig. 2. Effect of different cryo- and lyoprotectants on the viability after freezethawing and freeze-drying: complex media; unless indicated otherwise $10 \%(\mathrm{w} / \mathrm{w})$ solutions were used. The error bars show the standard deviation.

Figures 1 and 2 show the effect of freeze-thawing and freeze-drying. Fig. 1 shows the protection given by sugars and some inorganic compounds. Using a wide range of protectants, significant differences in the viability of cells of Lactococcus lactis after freeze-thawing and freeze-drying were observed, depending on the protectant used. When using sugars, disaccharides gave better 
viabilities than monosaccharides. $15 \%$ sucrose (39\% viability) gave the best viability. Fig. 2 shows the results yielded by complex media. The most effective mixtures as protective agents were $10 \%$ skim milk/sucrose (62\% viability), $20 \%$ skim milk/sucrose $(60 \%$ viability) as well as MRS-broth $+5 \%$ skim milk/sucrose (62\% viability) and MRS-broth $+5 \%$ mannitol (62\% viability). These mixtures combine good bulking agents with sugars.

\section{Effect of initial cell count on survival during lyophilisation}

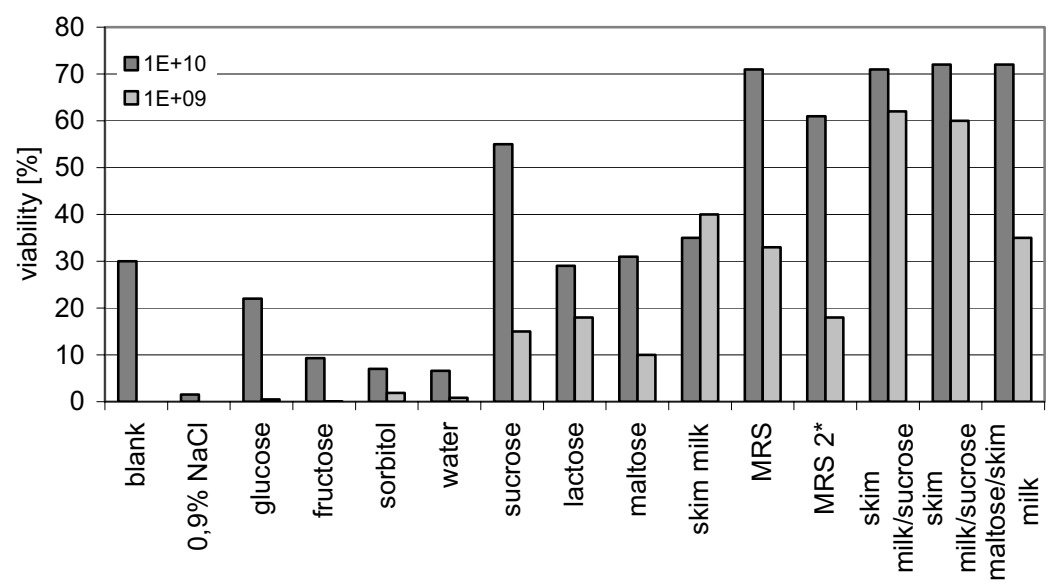

protectant

Fig. 3. Effect of the initial cell count on the viability after freeze drying.

In general, the viability obtained when skim milk/sucrose mixtures were used as protective agents was higher than that obtained with MRS-broth or sugars alone as protectors. Moreover, results showed that the effect of initial concentration had a marked dependence on the type of protectants used. For good protectants, the improvement attributed to higher cell concentrations was small whereas the increase of viability for less suitable protectants was noteworthy. Especially the 
blank (sample without protectants) yielded a 1500 fold (from $0,02 \%$ to $30 \%$ ) higher viability when $10^{10} \mathrm{cfu} \mathrm{ml}^{-1}$ as initial cell load was used instead of $10^{09} \mathrm{cfu} \mathrm{ml}^{-1}$. $10 \%$ skim milk/sucrose yielded only an 1,7 fold increase of viability (from $62 \%$ to $71 \%$ ) The results can be seen in Fig. 3. The protective effect of a higher cell count in the solution subjected to freeze-drying can be seen best when compared to the effect on bacteria lyophilised without protective agents (=blank).

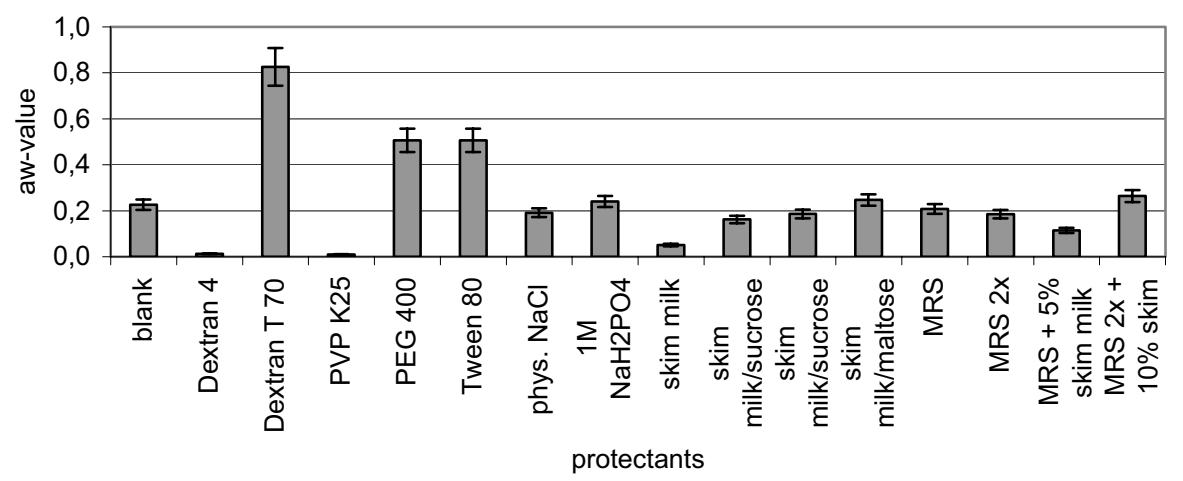

Fig. 4. Water activity $\left(a_{w}\right)$ value after lyophilization using different protectants. The error bars show the standard deviation.

For some samples, the $a_{w}$-value after lyophilisation was estimated. As seen in Fig. 4 the $a_{w}$-value is highly dependant on the nature of the protectant used. This is also of interest for optimizing the shelf life of the lyophilisated product. Ongoing investigations suggest that the shelf life depends to a certain degree, on the $a_{w}-$ value. The higher the $a_{w}$-value after lyophilisation the lower the shelf life stability. The protectant itself is much more important for good stability. The influence of different $a_{w}$-values after lyophilisation using the same protectant have not been estimated yet. 


\section{Discussion}

Freeze-drying has been studied as a dehydration process for bacteria in order to achieve a solid formulation. This study showed the impact of protective additives on the viability after freeze-thawing and freeze-drying. Also the influence of the initial cell concentration was estimated. It was demonstrated that Lactococcus lactis is quite resistant to freezing, thawing and dehydration during the processes of freezing and freeze-drying, which is useful from a commercial viewpoint. This result was expected because many bacteria are known to survive lyophilisation well [1]. The differences exhibited in cell survival in this study indicated that certain additives are more effective than others in protecting Lactococcus lactis. Maximum protection of cells during freeze-drying was achieved with sucrose/skim milk mixtures and MRS-broth-based protectants. All these protectants include sugars. Differences exhibited by sugars are related to their water-binding capacity and prevention of intracellular and extracellular ice crystal formation [21, 22]. This explains why disaccharides gave better viabilities after freeze-drying than monosaccharides.

As high cell concentrations are necessary for the production of commercial probiotic products it is useful to increase the initial concentration as much as possible to optimize the industrial process. In the case of Lactococcus lactis, the effect of initial cell concentration is related to the protective medium used. [23] suggested that the death of microorganisms is proportional to their area of contact with the external medium. All protective agents used yielded lyophilisates with higher recovery at high concentrations $\left(10^{10} \mathrm{cfu} \mathrm{ml}^{-1}\right)$.

In conclusion, this study has shown that the recovery of cells of Lactococcus lactis, when subjected to freeze-drying, depends on the protective media used and on the initial bacterial cell load. An appropriate selection of these factors seems to be essential for obtaining maximum viability of cells for industrial use. Future research must focus on the influence of the rehydration media on the viability after freeze-drying and on the optimization of the shelf life of the freeze-dried products. 


\section{References}

[1] Miyamoto-Shinohara $\mathrm{Y}$, Imaizumi T, Sukenobe J, Marakami Y, Kawamura S Komatsu Y.

Survival rate of microbes after freeze-drying and long-term storage.

Cryobiology 2000; 41: 251-5

[2] Jennings T A,

Lyophilisation. Introduction and Basic Principles.

Denver: Interpharm Press, 1999

[3] Abadias M, Benabarre A, Teixidò N, Ursal J, Vinas I.

Effect of freeze drying and protectants on viability on the biocontrol yeast candida sake.

International Journal of Food Microbiology 2001; 65: 173-82

[4] Crowe J H, Carpenter J F, Crowe L M, Anchordoguy F J.

Are freezing and dehydration similar stress vectors? A comparison of modes of interaction of stabilizing solutes with biomolecules.

Cryobiology 1990; 27: 219-31

[5] Avis K E, Wagner C M.

Cryopreservation Applications in Pharmaceuticals and Biotechnology.

Denver: Interpharm Press, 1999

[6] Leslie S B, Israeli E, Lighthart B, Crowe J H, Crowe L M.

Trehalose and sucrose protect both membrane and proteins in intact bacteria during drying.

Applied and Environmental Microbiology1995; 61: 3592-7

[7] Champagne C P, Mondou F, Raymond Y, Roy D.

Effect of polymers and storage temperatures on the stability of freeze-dried lactic acid bacteria.

Food Research International 1996; 29: 555-62

[8] Kets E P W, Teunissen P J M, de Pont J A M.

Effect of compatible solutes on survival of lactic acid bacteria subjected to drying.

Applied and Environmental Microbiology 1996; 62: 259-61

[9] Lorca G L, de Valdez G F.

Temperature adaption and cryotolerance in Lactobacillus acidophilus.

Biotechnology Letters 1998; 20: 847-9

[10] Broadbent J R, Lin C.

Effect of heat shock and cold shock treatment on the resistance of Lactococcus lactis to freezing and lyophilisation.

Cryobiology 1999; 39: 88-102

[11] Lodato P, de Huergo M S, Buera M P.

Viability and thermal stability of a strain of Saccharomyces cerevisiae freezedried in different sugars and polymer matrices.

Applied and Microbiological Biotechnology 1999; 52: 215-20 
[12] Louis P, Trüper H G, Galinski E A.

Survival of Escherichia coli during drying and storage in the presence of compatible solutes.

Applied and Microbiological Biotechnology 1994; 41: 684-8

[13] Cárcabo R, Rodríguez A.

Influence of cryoprotectants on the viability and activity of frozen and freeze dried cells on the novel starter strain Lactococcus lactis ssp. lactis CECT 5180.

Eur. Food Res. Technol. 2000; 211: 433-7

[14] Cerrutti P, de Huergo M S, Galvagno M, Schebor C, Buera M D P.

Commercial baker's yeast stability as affected by intacellular content of trehalose, dehydration procedure and the physical properties of external matrices.

Applied and Microbiological Biotechnology 2000; 54: 575-80

[15] Conrad P B, Miller D P, Ciebski P R, de Pablo J J.

Stabilisation and preservation of Lactobacillus acidophilus in saccharide matrices.

Cryobiology 2000; 41: 17-24

[16] Hubálek Z.

Protectants used in the cryopreservation of microorganisms.

Cryobiology 2003; 46: 205-29

[17] Carvalho A S, Silva J, Ho P, Teixeira P, Malcata F M, Gibbs P.

Relevant factors for the preparation of freeze-dried lactic acid bacteria.

International Dairy Journal 2004; 14: 835-47

[18] Costa E, Usall J, Teixido N, Garcia N, Vinas I.

Effect of protective agents, rehydration media and initial cell concentration on viability of Pantoea agglomerans strain CPA-2 subjected to freeze-drying.

Journal of Applied Microbiology 2000; 89: 793-800

[19] Palmfeld J, Hahn-Hägerdal B.

Influence of culture $\mathrm{pH}$ on survival of Lactobacillus reuteri subjected to freeze drying.

International Journal of Food Microbiology 2000; 55: 235-8

[20] Mugnier J, Jung G.

Survival of bacteria and fungi in relation to water activity and the solvent properties of water in biopolymer gels.

Applied and Environmental Microbiology 1985; 50: 108-14

[21] Baumann D P, Reinbold G W.

Preservation of lactic cultures.

Journal of Dairy Science 1964; 47: 674

[22] Burke M J.

The glassy state and survival of anhydrous biological systems.

In Membranes, Metabolism and Dry Organisms ed. Leopold, A.C.

Ithaca: Cornell University Press, 1986: 358-63 
[23] Bozoglu T F, Ozilgen M, Bakir U.

Survival of kinetics of lactic acid starter cultures during and after freeze drying.

Enzyme Microbial Technology 1987; 9: 531-37 